free fatty acids, which are to a large extent saponified by the alkali present, and the bromine is by the same agency converted into alkaline bromide. The bile then causes solution of this saponified mass of soap, fatty acid, and alkaline bromide, the latter by its easy solubility passing off in the urine. Considering the close combination of the bromine atoms in the molecules of the fatty acids and the general stability of the compound brominol it is remarkable from a chemical aspect that the balogen is absorbed to the extent to which analyses of the urine show to be the case. It may be put forward that the work to be done by the bile and tissues in converting the bromine into this soluble form is probably advantageous in producing its necessary effect in nerve trouble.

In conclusion, I consider that these balogenised fats deserve a more extended trial because I think that it may be argued that in some cases this ingestion may prove of benefit where the alkaline bromide by reason of its great solubility would pass off rapidly without producing its full action.

New Cavendish-street, $\mathrm{W}$.

\section{TWO CASES OF CARCINOMA TREATED WITH CACODYLATE OF SODA.}

\section{By EDWARD MARTEN PAYNE, M.B., C.M. ABerd.}

ThE idea of treating cancer with arsenic is not new. There was a story told of a German countess who, being stricken with the complaint, was so horrified that she determined to forestall a lingering and painful death by taking a large dose of arsenic which, however, instead of killing the countess, cured the cancer.

CASE 1.- On Jan. 14th, 1900, I was consulted by a patient, aged about 45 years, relative to irregular and rather profuse discharges of blood from the vagina. She attributed the occurrence to the "change of life," and as she objected to a physical examination I prescribed a mixture of ergot and sulphuric acid, which stopped the floodings for the time being. On April 17th I was consulted again and this time I made a vaginal examination but found no very definite signs except a certain amount of purulent discharge, from which the patient said she had suffered for a long time. The ergot and sulphuric acid mixture was again prescribed and the patient was better in two days. On June 13th I find she had another bottle of the mixture, but she did not consult me again until August 14th. She would not be examined, so I prescribed the old mixture and she went away to the seaside. On Oct. 5th I received an urgent message to go to see her at her own house. She had had a very severe attack of hæmorrhage while she was in the country and a medical man who had been called in had told her that she had cancer of the womb and had not long to live. This time I insisted upon making an examination and I found that the cervix was ulcerated and that there was fixation of the uterus. As the patient and her friends were extremely unwilling to believe that the disease was of a malignant nature I, after a good deal of difficulty and delay, persuaded them to let me call in a well-known gynæcologist who confirmed the diagnosis and who said that operative meth ids would be useless. This was on Nov. 29th. For the sake of doing something I had already been treating the case with Fowler's solution, and on Dec. 16th I commenced hypodermic injections of cacodylate of soda. On the first day $I$ injected two centigrammes, on the next four centigrammes, and on the next five centigrammes, and I kept up the last-named dose daily until Jan. 16th, 1901, when I increased the daily dose up to 7.5 centigrammes, which was the maximum dose that I employed in this case. The injections were continued daily, with occasional intermissions, until Feb. 25th, when the patient got so tired of the needle that at her earnest request $I$ let her have a mixture containing the drug in doses of 25 centigrammes which she took three times a day until March 14th, when for some reason or other she suddenly refused to go on with the treatment.

As to the results, unfortunately I could never get $\mathrm{my}$ patient to let me make another vaginal examination, so I was obliged to form my conclusions on other data. As to the general state of the patient's health she and all her friends agreed that there was a great improvement. She left her bed and took walks out of doors, and even travelled all the way from the distant suburb where she lived to look at the shops in Regent-street. Her colour improved. She wore close-fitting dresses which had been made for her a year ago and they fitted her exactly still. She gained weight, as much as two pounds in three weeks. The hæmorrhage ceased and the white discharge diminished. When the patient was at her work she had complained much of constipation which I believed to be due to pressure of the tumour on the rectum. This condition also became very much improved. In short, the patient herself got so much better that she finally declared that she could never have had cancer, and this was her excuse for giving up the treatment.

CASE 2. - The next case I shall describe is one of an old man, aged about 70 years. On August 2nd, 1900, he complained of a sore mouth and tongue. The tongue was a little ulcerated. There were several jagged old teeth and stumps which were thought to be the offenders, the tongue was a little swollen generally, but there was no localised swelling. A mouth-wash was supplied and after some persuasion two teeth were extracted on Sept. 10th and another one on Nov. 24th. There were no more complaints about the mouth until March 14th, 1901, when the patient told me that he felt as if he had a hole in the middle of the tongue. On examination it was found that there was a deep depression in the middle of the upper surface of the organ, and immediately beneath the depression was a hard substance of about the size of a large filbert. I suspected carcinoma, so I made known to the friends of the patient my apprehension and suggested that a specialist should be consulted. They did not care to have a specialist, but my partner, Dr. Whitehall Cooke, kindly came and after examining the patient he expressed his conviction that the case was one of carcinoma. We both agreed that considering the patient's age an opera. tion was not advisable. On March 17th I commenced hypodermic injections of cacodylate of soda, beginning with a small dose and gradually increasing it to 7.5 centigrammes. From the first the patient said that he felt much better in himself and at the present time, after about six weeks' treatment, I am sure the swelling under the tongue is no larger ; indeed, I think that it is less and that the surface of the tongue is less retracted. There is less soreness of the gums bat it is not always absent. On one occasion I noticed that some of the lymphatic glands in the neck were swollen but the swelling subsided in a few days. On the outer surface of the inferior maxillary bone about the region of the left incisive fossa a swelling appeared about the time the treatment was commenced; this also has subsided somewhat.

I have given the above notes for what they may be worth, for although I fear that I cannot claim that the results I have recorded are of a very decisive nature I am myself strongly inclined to the opinion that cacodylate of soda, even if it cannot claim to be a cure for the cancer, is at least a very valuable palliative. It certainly seems to arrest the progress of the disease and it improves the patient's general condition, and $I$ am of opinion that it should at least be tried in those cases where early operative methods are out of the question.

I have a theory of my own as to how arsenic acts in cases of cancer. It is well known that arsenic, which is so much prescribed in "skin diseases," has, if pushed too far, a deleterious effect on that organ. An excellent series of cases bearing on this subject is given by Mr. J. Hutchinson in the Polyelinic. ${ }^{1}$ Amongst these several cases are recited in which the continuous use of the drug bas been said to produce cancer and cancerous ulcers, or, at any rate, growths and ulcers, which appeared to be mor. phologically identical with cancer when examined under the microscope. Now in view of the theory which has of late years been revived and is at the present time in growing favour with pathologists-viz., that cancer is due to the irritation of the epithelial cells by a specific micro. organism-may we not fairly question whether, after all, these growths and ulcers which have been attributed to the effect of arsenic are really pathologically identical with the growths and ulcers known as cancers? If cancer be due to the irritation of the epithelial cells by a specific organism then these ulcers and growths either are not cancerous or if they are they are not due to the arsenic but occur coincidently only with its administration, unless, indeed, it be maintained 
that the arsenic acts as a secondary or exciting cause by which the dormant energies of the latent micro-organism are stimulated to action. Now there are so many of these cases quoted that it does not seem probable that the appearance of these cancers is purely coincidental, although it might happen that the cancer was the ultimate manifestation of an abnormal condition of the epithelial cells which at first showed itself in the shape of the psoriasis or whatever it was that was the primary object of treatment. The theory that the arsenic stimulates the dormant organisms into a state of activity seems too far-fetched to be accepted without further evidence, so we are thrown back upon one or the other of the following suppositions-viz., that the growths and ulcers following excessive doses of arsenic are not truly cancerous but are pathologically distinct although morphologically similar; or that cancer is a growth having a certain morphological structure pathologically due to some epithelial irritant and that amongst such irritants arsenic is one. In any case it seems certain that arsenic has a specific action on the epithelial cells, at first beneficial, ultimately destructive. It also seems to be a plausible theory that on coming in contact with the epithelial cells in a person suffering from cancer its deleterious effects would be resisted more vigorously by the normal physiological cells, while pathological cancerous cells would be the first to be overcome and destroyed.

Cricklewood, N.W.

\section{ACUTE COLITIS IN CHILDREN. ${ }^{1}$}

Br EDMUND CAUTLEY, M.D. CaNTAB., \&c.,

PHYSICIAN TO THE BELGRAVE FOSPITAL FOR CHILDREN; ASSISTANT PHYSICIAN TO THE METROPOLITAN HOSPITAL.

IT is a remarkable fact that the occurrence of acute colitis, or ileo-colitis, in epidemic form is almost unknown, or at any rate unrecorded, in England. Even in America, where diarrhoeal affections in children are more common and more severe during the hot season than in England, the disease does not appear to have attracted attention as an epidemic. A small but very definite outbreak has recently come under my observation and is well worthy of publication. Six out of 30 children were affected and of these patients four died. Four of them came under my care, two of whom died. Three out of 13 adult women were attacked less severely and recovered. The first case I saw in consultation with Mr. D. Boyd Keown who kindly agreed to transfer the child to the Belgrave Hospital for Children for treatment and has since supplied me with the following particulars of the epidemic.

Habitation.-All the cases broke out in certain London barracks, in rooms opening on to a common staircase. On this particular staircase there are four floors with four rooms on each floor. 13 families, consisting of 13 women and 30 children, occupied these 16 rooms, three of the larger families having two rooms apiece. On the third floor lived three women with two, two, and five children respectively. The first case broke out on this floor on June 20th, 1900, and the second on June 30tb. Two out of the family of five children were affected and both died (Case 1 and Case 2). On the second floor lived three women, one of whom had four children. No case occurred on this floor. On the first floor lived three women, one of whom had four children, another bad five children, while the third had none. The last cases broke out here at the beginning of August. The mother of five and two of her children were attacked and one of the children died. On the ground floor lived four women with three, three, two, and no children respectively. The family of the mother and two children were all affected, the first on July 14th, and of these the younger child died. One of the women with three children was attacked, but not severely, and her children escaped. Thus the epidemic started on the top floor, then broke out on the ground floor and finally on the first floor.

Etiology.-As far as could be ascertained by personal inspection no fault could be found with the water-supply, the lavatory accommodation, or the drainage inside the building. Just outside the entrance a pipe, carrying the rain-water from the roof, opened into a gully from which

1 A paper read before the Medical Society of London on May 13th, the grating had been removed. This gully was frequently full of stagnant offensive water, and in one instance (Case 3 ) the child bad been noticed putting her hands in the water and then in her mouth. It must, however, be pointed out that other children living on adjacent staircase had access to this water and that the outbreak was limited to the one staircase. The milk-supply for the families affected came from two different milkmen. The foodsupplies were bought outside the barracks. A very careful investigation by Mr. Keown and myself did not enable us to ascertain what the source of infection had been. Although the cases occurred during the hot months of the year the weather was colder than usual at the time.

The following are short details of the four cases which came under my charge.

CASE 1.-A girl, aged five years, was admitted into the Belgrave Hospital for Children on June 28th, 1900, and she died on July 1st. On June 22 ad the family had some fried mackerel of which the child partook. Vomiting and diarrhoea began at 4 A.M. next day and persisted in spite of treatment. On admission the child was very ill and cold and wasted; the temperature was normal and the pulse was 140 . Nothing abnormal was found on physical examination. The abdomen was lax and empty and it was nowhere tender. Vomiting continued. The diarrhcea was profuse as regards frequency, 20 stools being passed on the 29 th and 14 on the next day. The stools were small, sometimes not more than a tablespoonful at a time, green, containing mucus and blood, and very offensive. There did not appear to be any pain or tenesmus, though there was a history indicating a certain degree of tenesmus. The child rapidly got weaker and she died from exhaustion at $2.25 \mathrm{~A} . \mathrm{M}$. on July 1 st. The temperature reached $101^{\circ} \mathrm{F}$, a few hours before death.

CASE 2.-A boy, aged three years, was admitted to the hospital on July 1st, 1900 , and he died on the $8: \mathrm{h}$. The patient was brother of the first child and they had slept in the same bed. He was quite well until the afternoon of June 30th and was a fine, strong, well-nourished boy. Illness began with abdominal pain, vomiting, and diarrbca. On admission his temperature was $103^{\circ} \mathrm{F}$., the pulse being 144 and the respirations 36 . Nothing abnormal was found on physical examination. Possibly the abdomen was a little distended, but there was no tenderness. The course and symptoms were the same as in the first case. The stools numbered from 11 to 20 in the 24 hours; they were small and green, containing bright red blood, mucus, and a little fæcal matter, and were very offensive. Vomiting was tronblesome and persistent. On the day before death he brought up some blood. He took food badly, was very restless, and he died from exhaustion. No other cases occurred in this family. Temperatures were taken every four hours, the highest and lowest readings Fahrenheit for each day being as follows :-July 1st highest $103^{\circ}$; lowest, $98.8^{\circ}$. July $2 \mathrm{nd}$ : highest, $101.4^{\circ}$ lowest, $98^{\circ}$. July 3rd : highest, $1008^{\circ}$; lowest, $98.8^{\circ}$ July 4th: highest, $1008^{\circ}$; lowest, $982^{\circ}$. July 5 th : highest $101^{\circ}$; lowest, $98 \cdot 2^{\circ}$. July 6 th : highest, $100 \cdot 2^{\circ}$; lowest, $97 \cdot 4^{\circ}$. July 7 th : highest, $998^{\circ}$; lowest, $97 \cdot 2^{\circ}$

OASE 3.-A female infant, aged two years, was admitted into the hospital on July 18th, 1900, and was discharged cured on August 27th. She was the elder of two, the other being a baby at the breast. It could not be ascertained that the illness was due to any deleterious article of diet, but on July 13th, the day preceding the onset, the child was noticed putting her hands into the dirty water previously mentioned and then into her mouth. On the 14 th she was languid and had diarrhoea. In the evening she vomited after taking medicine and she had a little colic. Next day the vomiting was continuous and the diarrhœa was worse, with a large amount of blood in the stools. The hæmorrhage was severe on the following day and then it diminished, more mucus being passed. On admission she had a temperature of $101^{\circ} \mathrm{F}$., was well-nourıshed, and presented a moderate degree of abdominal distension, without pain or tenderness. The fever lasted for a fortnight; it was rarely up to $100^{\circ} \mathrm{F}$. Vomiting ceased on the $20 \mathrm{th}$. The diarrbcea persisted for a fortnight, the stools becoming less frequent and more fæcal. They were never as numerous as in the first two cases, 12 being the maximum number in the 24 hours. At first they presented the usual characteristics and were very green. No blood was seen after the 31 st and no mucus after a few more days. The stools were unformed and offensive for a further 10 days and after that they became normal. At first the child was very ill, lethargic, and fed badly, but she improved 